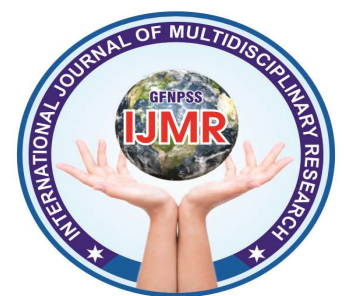

\title{
A PRE EXPERIMENTAL STUDY TO ASSESS THE EFFECTIVENESS OF STRUCTURED TEACHING PROGRAMME ON KNOWLEDGE REGARDING PLACENTAL AND UMBILICAL CORD EXAMINATION AMONG STAFF NURSES IN SELECTED MATERNITY HOSPITAL AT JAIPUR
}

\author{
SEHJO RANI', ANUPAMA JAIN ${ }^{2}$ \\ ${ }^{1}$ M.Sc.Nursing OBG, Jaipur Hospital College of Nursing, Jaipur, Rajasthan \\ ${ }^{2}$ Associate Professor, Jaipur Hospital College of Nursing, Jaipur, Rajasthan
}

Corresponding Email: sehjo.rani1984@gmail.com, anupamajain1980@gmail.com

\begin{abstract}
:
Introduction: Birth of a fetus for a mother is a special moment of joy with lot of expectations. However the first minute after birth is full of anxious moments and rapid physiological adjustments. Placental and umbilical cord examination performed by skilled personnel is necessary in reducing the mortality and morbidity among mother and fetus.

Materials and methods: pre experimental one group pretest - postest research design was used in this study. Purposive sampling technique was used to select the samples.60 staff nurses working in jaipuria hospital, Jaipur were included in the study. The data was collected and organised for data analysis.

Result: The mean post-test knowledge score $(\mathrm{X} 2=23.65)$ was higher than the mean pretest knowledge score $(\mathrm{X} 1=17.08)$. The mean percentage knowledge score of pre-test was maximum in the area of mechanism - placental and umbilical cord examination (59.24\%) and minimum in the area of causes and important points to follow during examination $(43.33 \%)$ whereas the mean percentage knowledge score of post-test was maximum in the area of nurses responsibility and complications In placental and umbilical cord examination and less in the area of in the area of Mechanism (77.95). The mean difference between post-test and pre-test knowledge score was highly significant.
\end{abstract}

Conclusion: The study had shown that majority of the staff nurses had inadequate knowledge on placental and umbilical cord examination.

Keywords: Effectiveness, Structured Teaching Programme, examination, knowledge.

\begin{tabular}{ccc}
\hline Received & Accepted & Available online \\
\hline $10 / 09 / 2021$ & $20 / 09 / 2021$ & $03 / 10 / 2021$ \\
\hline
\end{tabular}




\section{INTRODUCTION:}

Placenta, a fascinating multifunctional organ, of fetal origin, plays a pivotal conciliatory role during pregnancy by being intimately connected to the mother and her baby. The importance of placenta is irrefutable, being an exceptional (and easily-accessible) source of information which echoes the intrauterine environment.

The umbilical cord is the lifeline between the fetus and placenta. It is formed by the fifth week of development and it functions throughout pregnancy to protect the vessels that travel between the fetus and the placenta. Compromise of the fetal blood flow through the umbilical cord vessels can have serious deleterious effects on the health of the fetus and new baby.

Examination of the placenta is performed for fetal, maternal, and placental indications. The purposes are to identify fetal or maternal disease, to provide prognosis for the current and future pregnancies, to evaluate the effect of maternal disease on the pregnancy, and for legal considerations . Many placental lesions are diagnosed solely by gross examination, and the extent of the pathologic processes is best recognized on the whole specimen. Meticulous gross examination of a placenta prior to histologic sectioning enhances microscopic interpretation. Ideally, clinical information is available at the time of gross examination, including duration of gestation, fetal weight, and any problems related to the pregnancy, birth, or fetus/neonate.

A one-minute examination of the placenta performed in the delivery room provides information that may be important to the care of both mother and infant. Based on the review of literature and clinical experience the investigator came across many mothers who had delivered, the babies being still born, cerebral palsy, IUGR, hypospadiasis, neurological deficit and also fetal death and maternal complication such as puerperal sepsis, post partum hemorrhage etc.,this is indirectly related to placental health. So the examination of placenta can provide the evidence needed to determine the biological cause of prenatal or developmental abnormality .Hence the investigator determined to 


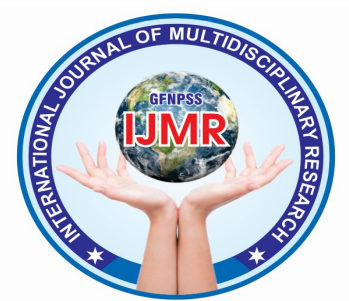

explore the knowledge level of staff

and umbilical cord examination among

nurses at selected hospital regarding

placenta and its examination and to

staff nurses with selected socio

give structured teaching programme on

placenta examination.

\section{OBJECTIVES OF THE STUDY:}

To assess per test knowledge score of staff nurses regarding placental and Umbilical cord examination in selected maternity hospital.

To determine effectiveness of STP by comparing the pre-test and post test knowledge scores regarding Placental and umbilical cord examination among staff nurses in hospital.

$>$ To find out the association between pre- test knowledge score of staff nurses regarding placental and umbilical cord examination with selected socio demographic variables.

H1 -The mean post-test knowledge score of staff nurses regarding Placenta and umbilical cord examination will be significantly higher than the mean pretest knowledge score.

H2 -There will be significant association between pre-test demographic variables.

\section{MATERIALS AND METHODS:}

An evaluatory approach with preexperimental one group pre-test post-test design was used for this study. The study was carried out in Jaipuria, hospital, Jaipur. The sample comprised of 60 staff nurses who met the inclusion criteria and were chosen by purposive sampling technique. Formal written permission was obtained from the authorities to conduct the study .Data was collected by administering a structured knowledge questionnaire before and after the administration of structured teaching programme. A post-test was conducted on the 7 th day using the same tool. The data was analyzed using descriptive and inferential statistics to find the effectiveness of structured teaching programme and chi-square was used to find the association of pre-test knowledge score with selected demographic variables.

\section{RESULTS AND FINDINGS:}

Significance difference between pretest and post-test knowledge scores knowledge score regarding placental

\section{$\mathrm{N}=\mathbf{6 0}$}




\begin{tabular}{|c|c|c|c|c|c|c|c|c|}
\hline \multirow[t]{2}{*}{ S.No } & \multirow[t]{2}{*}{ Score } & \multirow[t]{2}{*}{ Mean } & \multirow{2}{*}{$\begin{array}{l}\text { S. } \\
\text { D }\end{array}$} & \multirow{2}{*}{$\begin{array}{l}\text { Std } \\
\text { error }\end{array}$} & \multirow{2}{*}{$\begin{array}{l}\text { Mean } \\
\text { differen } \\
\text { ce }\end{array}$} & \multirow[t]{2}{*}{ D.F } & \multicolumn{2}{|l|}{ 't'table } \\
\hline & & & & & & & $\begin{array}{l}\text { Calculat } \\
\text { ed } \\
\text { value }\end{array}$ & \begin{tabular}{|l} 
Tabulate \\
d \\
value
\end{tabular} \\
\hline 1 & Pre-tes & 17.08 & $\begin{array}{l}4.3 \\
1\end{array}$ & 0.82 & 6.57 & 59 & 8.01 & 2 \\
\hline 2 & $\begin{array}{l}\text { Post- } \\
\text { test }\end{array}$ & 23.65 & $\begin{array}{l}4.6 \\
6\end{array}$ & & & & & \\
\hline
\end{tabular}

The result shows that post-test mean score was significantly higher than the pre- test mean score. The tabulated value of' $t$ ' score at $5 \%$ level of significance and 59 degrees of freedom is 2 and the table value was less than the calculated' value (8.01)which represents the significant gain in knowledge through the structured Teaching Program. Thus it suggests that the STP has been effective in increasing the knowledge of staff nurses about placental and umbilical cord examination. $(\mathrm{p}<0.05 \mathrm{HS})$

\section{CONCLUSION:}

The following conclusions were drawn on the basis of the findings of the study:

The pre-test knowledge scores among most of the staff nurses were poor and average.

$>$ The introduction of the STP among the staff nurses helped them to learn more about placental and umbilical cord examination, which was evident, in the post- test knowledge scores.

The STP proved its validity as one of the effective teaching method of information transmission. It was well appreciated and accepted by the staff nurses.

The chances for the better practice in neonatal resuscitation could be anticipated. The study paved the path to find a variety of other information on placental and umbilical cord examination.

\section{REFERENCES:}

01. https: //embryology. med .edu. Au/ embryology/ index .php / placenta abnormalities.

02. Journal of clinical and diagnostic research ",table of contents - years: 2013 / month: Nov. / volume: 7 / issue :11/ page : 2530- 2533.

03. Ruth Bennett, Linda K. Brown, "Myles Text book for Midwives" 14th edition 2003. PP 143.

04. Heifetz SA. the umbilical cord; obste triccally important lesion, clinobest gynecol 1996;39:571-87

05. Kuhlmann RS, Warsof S, Ultrasound 


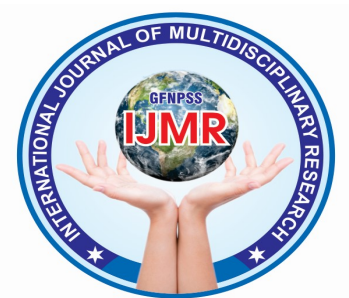

of the placenta; ClinObstetGynecol

fetal death 1992 jul; 27(4): 214-6, 250.

1996; 9: 519-34.

09. Salgado SS, PathmeswaranA J Coll

06. Accreta T. Yee Khong MD and Alice Physicians surgpak 2008 Apr; 18(4):

C.Werger “Am J clinPathol” 2001:116; 703- 708 . 213-616.Garner P, Lai D, Bara M, “ childbirth in rural areas PNG Med J.

07. Salafia CM, VintzileosAM, Silberman L, Bantham KF, Vogel CA. Department of Laboratory Medicine, Am J Perinatol.1992 May; 9(3): 17984.

08. Zhonghua FU Chan KeZaZhi "The significance of pathological examination of the placenta in exploring the causes of intrauterine 1994 Sep;37(3):166-72.

10. Amato NA, Maruotti G, Scillitani G, Lombardi L, Pietropaolo F, Unitaoperativa di Ginecologis E ostetricia "Minerva Ginecol 2007 Aug; $5 \mathrm{~g}(4): 357-67$.

11. Polit DF, Hungler BP, Nursing research, principles and methods. 6th edition. Philadelphia:Lippincott company 2005 Pg 117. 